\title{
CLINICAL AND HÆMODYNAMIC OBSERVATIONS ON COMBINED MITRAL AND AORTIC STENOSIS
}

\author{
BY \\ M. HONEY* \\ From the Cardiac Department, Guy's Hospital \\ Received April 1, 1961
}

The association of significant aortic stenosis with mitral stenosis in rheumatic heart disease is not very common. It is, however, important to recognize the presence of the accompanying aortic stenosis and to be able to assess its severity, since this lesion also can be relieved surgically. The clinical and hæmodynamic features of 35 patients, seen at Guy's Hospital between 1952 and 1959, with this combination of lesions have been studied in order to learn more about the ways in which each lesion modifies the effects of the other: these observations have been applied to the problems of diagnosis and assessment of severity.

\section{MATERIAL AND MethodS}

This series includes those patients (32) in whom an estimate of the mitral valve area has been made by the surgeon, and in whom aortic stenosis was suspected clinically and confirmed by the demonstration of a systolic gradient across the aortic valve, at operation for mitral or combined mitral and aortic valvotomy. Seventeen of these had a pre-operative right heart catheterization, together with a left ventricular puncture in three and a left atrial puncture in three. Two unoperated patients have had full hæmodynamic assessment by left atrial puncture; one of these died while awaiting operation and one was thought not to require surgical relief of either stenosis. In one operated patient, a small aortic valve gradient was demonstrated at left atrial puncture but not measured at operation.

None of the 35 patients had dominant regurgitation at either valve. In 23, an early diastolic murmur thought to be due to slight aortic regurgitation was recorded, but in only two was this possibly of hæmodynamic significance. In 12 of the 33 operated patients, slight mitral regurgitation was detected, but in none was this sufficient to contraindicate valvotomy; in the 2 unoperated patients, the clinical features suggested dominant mitral stenosis, though both had apical systolic murmurs. Three (Cases 8, 11, and 19) had organic tricuspid stenosis.

The presence or absence of those symptoms commonly occurring in lone mitral or aortic stenosis and the degree of disability (criteria of Baker et al., 1952) were noted. The findings on examination were not analysed since this was a retrospective study and only a few of the patients were personally examined before operation. The cardiogram was inspected for evidence of right or left or bi-ventricular hypertrophy; left ventricular hypertrophy (L.V.H.) was regarded as slight when the sum of the amplitudes of the deepest $\mathbf{S}$ wave in a right ventricular lead and the tallest $R$ in a left ventricular lead was 35 to $45 \mathrm{~mm}$., and moderate when 46 to $60 \mathrm{~mm}$.; changes in the S-T segment and T wave were of little value since most of the patients were receiving digitalis. The cardiac rhythm was also noted. The chest radiograph was examined for dilatation of the first part of the aorta and pulmonary venous congestion, and the screening report for observations on the presence of left ventricular hypertrophy and mitral or aortic valvar calcification and the aortic appearances.

Right heart catheterization was performed in the usual way: pulmonary artery and "pulmonary capillary venous" pressures were recorded with the reference zero level at the mid-thorax, and the cardiac index (cardiac output/body surface area in sq. m.) obtained using the Fick principle. Left atrial puncture was by

\footnotetext{
* Present address: St. Bartholomew's Hospital, London. This investigation was the subject of a communication to the British Cardiac Society in October, 1959.
} 
the posterior percutaneous route (Björk et al., 1954; Hancock, 1959a), the left ventricle being catheterized by introducing fine nylon or polythene tubing through the needle; left ventricular puncture was by the method of Brock et al. (1956); cardiac output was measured by the Fick principle or by a dye-dilution technique using an ear-oximeter (Hancock, 1959b); and aortic and mitral valve areas were calculated by the formula of Gorlin and Gorlin (1951), using the empirical constant $44 \cdot 5$ for both valves.

The following information was obtained from the operation report: the aortic peak systolic gradient (before and after mitral and aortic valvotomy), the presence of post-stenotic dilatation of the ascending aorta, the presence of calcification in the aortic valve cusps, the surgeon's rough assessment (where given) of the dimensions of the aortic valve orifice as estimated from the size of the instruments passed through it; the surgeon's assessment of the mitral valve area (approximate length and breadth of the orifice) as estimated by the exploring finger, the presence of palpable regurgitation (before and after mitral valvotomy), and the final orifice size. The degree of mitral stenosis was then classified as severe $(1.0 \times 0.5 \mathrm{~cm}$. or less), moderate $\left(1.0\right.$ to $1.5 \times 0.5$ to $1.0 \mathrm{~cm}$.), or mild $\left(>1.5 \times 1.0 \mathrm{~cm}\right.$.) ${ }^{*}$. When death occurred, information about the severity of aortic and mitral valve stenosis, valve calcification, post-stenotic dilatation, and left ventricular hypertrophy was sought from the necropsy report.

The post-operative course of these patients is being reported elsewhere (Honey, 1961), the same case numbers being used in both papers.

\section{RESULTS}

The age and sex distribution is given in Table I. Thirty of the 35 patients were in the fourth and fifth decades and the average age of the whole group was 40 years. Roughly two-thirds (71\%) were women. A clear history of rheumatic fever or chorea was obtained in about two-thirds (Table I).

TABLE I

Age, SeX, ANd Rheumatic History

\begin{tabular}{|c|c|c|c|c|c|c|c|c|c|}
\hline \multirow{2}{*}{\multicolumn{2}{|c|}{ Sex Men 10 Women 25}} & \multirow{2}{*}{ 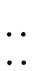 } & \multirow[b]{2}{*}{$\begin{array}{l}\cdots \\
\cdots\end{array}$} & \multirow[b]{2}{*}{$\because 2$} & \multicolumn{5}{|c|}{ Rheumatic history } \\
\hline & & & & & Definite & .. & . & .. & $\ldots 25$ \\
\hline $30-39$ years & $\ldots$ & $\ldots$ & . & $\ldots 14$ & Probable & .. & .. & .. & $\ldots 4$ \\
\hline $40-49$ years & .. & $\ldots$ & . & $\ldots 16$ & None & .. & . & . & .. 6 \\
\hline 50 years + & . & . & . & .. 3 & & & . & & \\
\hline
\end{tabular}

TABLE II

SYMPTOMS

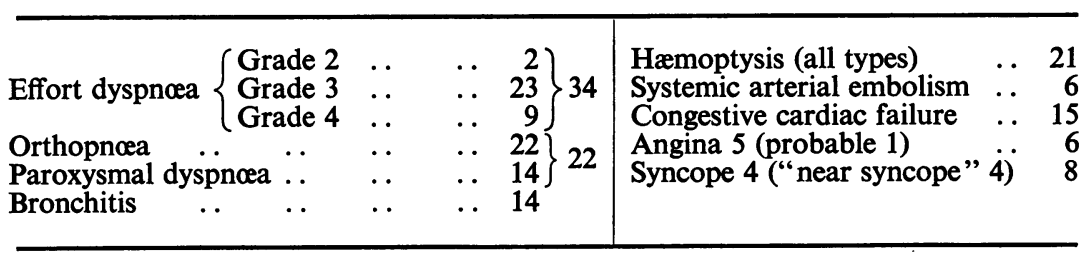

Symptoms (Table II). Only one of the patients (Case 34) had no limitation of exercise tolerance; her presenting symptom was repeated hæmoptyses. All but two of the remainder were severely disabled. Orthopnœa, with or without a history of paroxysmal dyspnœa, occurred in 63 per cent and hæmoptysis in 60 per cent. Recurrent bronchitis and cardiac œdema or frank congestive cardiac failure were common and systemic embolism had occurred in one-sixth. Angina and syncope or "near-syncope" (Baker and Somerville, 1959) were relatively infrequent.

The Electrocardiogram: Evidence of Left Ventricular Hypertrophy (L.V.H.). 60 per cent of the patients had atrial fibrillation and 40 per cent were in sinus rhythm. Two patients had a prolonged P-R interval, and one of these had tricuspid as well as mitral and aortic stenosis (Case 8). The

* One valve $2.0 \times 0.2 \mathrm{~cm}$. was classified as moderate and in one un-operated patient, a calculated valve area of $1 \cdot 5$ sq. $\mathrm{cm}$. was classified as mild. 
electrical position was horizontal in 4, intermediate in 5, and vertical or semivertical in the remainder. Right ventricular hypertrophy (R.V.H.) was present in 11 and probable in 5 others. L.V.H. was slight in 9 and moderate in 3 ; in one other, left bundle-branch block was present but previous cardiograms showed moderate L.V.H.; in another, a mean QRS axis of $-30^{\circ}$ may have denoted L.V.H. Thus some degree of L.V.H. was present in 14: it was never more than moderate in severity and that only in 4 patients. The presence of R.V.H. may in some cases have masked co-existent L.V.H.

Radiographic Features: L.V.H., Post-stenotic Dilatation, Aortic Valve Calcification. L.V.H. was reported at fluoroscopy in 14: in 11, this was Grade 1 and cardiographic L.V.H. was present in six of these; in 3, it was Grade 2 or 3 and in two of these there was cardiographic and necropsy confirmation, though in the other, the cardiogram did not show L.V.H. and the left ventricle was thought to be normal in size at operation. In 5 further patients, L.V.H. was thought to be probable and in 3 of these this was confirmed on the cardiogram. Thus in 11 patients there was both cardiographic and radiological evidence of L.V.H., but in only two was this more than slight by both techniques (Cases 5 and 10).

Prominence of the ascending aorta on the chest film was seen convincingly in only 4 patients. In a further 11, post-stenotic dilatation was observed by the surgeon at operation. In many of the chest films, it was noticed that prominence of the right pulmonary artery and its main branches, and in some hilar clouding due to pulmonary venous congestion obscured the right border of the heart in the region of the ascending aorta. This factor may have been partly responsible for failure to recognize prominence of the first part of the aorta but it is probable that the degree of dilatation in these cases was relatively slight.

Calcification of the aortic valve was observed fluoroscopically in only two patients (Cases 1 and 2 ); in 5 others, calcification was noted at operation (subsequently confirmed at necropsy in one of these); and in another, calcification was only revealed at necropsy. Thus in only 8 patients out of the 35 was recognizable aortic valve calcification present.

\section{HæmOdynamic ObSERVATIONS (TABLES III AND IV)}

Cardiac Index. Of the 21 patients in whom the cardiac output was measured, 16 had low cardiac indices of less than $2.51 . / \mathrm{min}$./sq. m. and only 5 had normal cardiac indices (more than $2.51 . / \mathrm{min} . / \mathrm{sq}$. $\mathrm{m}$.), the range being $1 \cdot 4$ to $5 \cdot 0$ and the average $2 \cdot 31 . / \mathrm{min} . / \mathrm{sq} . \mathrm{m}$.

Left Atrial Pressure. Left atrial or "pulmonary capillary venous" pressure was measured in 22 patients and was above the upper limit of normal $(12 \mathrm{~mm}$.) in all except 5, ranging from 7 to $33 \mathrm{~mm}$. (average $19 \mathrm{~mm}$.). Of the 5 patients with normal pressures, 3 had grossly reduced cardiac indices ( 1.4 to $1.91 . / \mathrm{min}$./sq. m.) and the other 2 had mild mitral stenosis and normal outputs.

Aortic Valve Gradient. This was measured at operation in 32 of the patients and in the other 3 at left atrial puncture only. The peak systolic gradient exceeded $75 \mathrm{~mm}$. in only 4 ; in 2 others gradients of $82 \mathrm{~mm}$. and $100 \mathrm{~mm}$. were obtained at pre-operative left atrial puncture, though at operation the gradient was lower. Two-thirds of the whole group had gradients of less than $50 \mathrm{~mm}$. and in no fewer than 13 the gradients were less than $25 \mathrm{~mm}$.

In the 6 patients in whom the aortic valve gradient was measured pre-operatively and at operation, the figure obtained at operation was lower in three (Cases 10,21, and 35), higher in one (Case 3), and showed only a small difference in the other two (Cases 2 and 4).

Pulmonary Artery Pressure and Pulmonary Vascular Resistance. The findings are recorded in Table III. Severe pulmonary hypertension was found in 6 patients, in three of whom the calculated pulmonary vascular resistance exceeded 10 units.

The Severity of the Mitral Stenosis. The surgeon's estimate of the size of the mitral orifice was available in 33 patients; in one, the valve was measured at necropsy; and in the other, the valve area was calculated from data obtained at left atrial puncture. In 16 patients it was classed as severe, in 14 as moderate, and in 5 as mild stenosis. In Fig. 1, the cardiac index is correlated with the severity 
TABLE III

Hemodynamic ObSERVATIONS ANd OPERATION Findings

\begin{tabular}{|c|c|c|c|c|c|c|c|c|c|c|c|c|c|}
\hline \multirow[b]{2}{*}{$\begin{array}{l}\text { Case } \\
\text { No. }\end{array}$} & \multirow[b]{2}{*}{$\begin{array}{l}\text { Age } \\
\text { Sex }\end{array}$} & \multirow[b]{2}{*}{$\begin{array}{c}\text { C.O. } \\
\text { (l./min.) } \\
\text { (C. Index) } \\
\text { (1./min./ } \\
\text { m.2) }\end{array}$} & \multirow[b]{2}{*}{$\begin{array}{l}\text { L.A. or } \\
\text { P.C.V. } \\
\text { mean pres- } \\
\text { sure at rest } \\
\text { (on effort) }\end{array}$} & \multirow[b]{2}{*}{$\begin{array}{l}\text { L.V. } \\
\text { Pressure }\end{array}$} & \multirow{2}{*}{$\begin{array}{c}\text { B.A. } \\
\text { Pressure }\end{array}$} & \multirow[b]{2}{*}{$\begin{array}{c}\text { Aortic } \\
\text { systolic } \\
\text { gradient } \\
\text { Peak } \\
\text { (mean) }\end{array}$} & \multirow[b]{2}{*}{$\begin{array}{l}\text { Calc. } \\
\text { A.V.A. } \\
\text { sq. cm. }\end{array}$} & \multirow[b]{2}{*}{$\begin{array}{l}\text { Calc. } \\
\text { M.V.A. } \\
\text { sq. cm. }\end{array}$} & \multirow[b]{2}{*}{$\begin{array}{c}\text { P.A. } \\
\text { pressure } \\
\text { S/D (mean) }\end{array}$} & \multirow{2}{*}{$\begin{array}{l}\text { P.V.R. } \\
\text { units }\end{array}$} & \multicolumn{3}{|c|}{ Operation findings } \\
\hline & & & & & & & & & & & $\begin{array}{l}\text { Aortic } \\
\text { systolic } \\
\text { peak } \\
\text { gradient }\end{array}$ & $\begin{array}{l}\text { M.V.A. } \\
(\mathrm{cm} . \times \mathrm{cm} .)\end{array}$ & $\begin{array}{l}\text { Mitral } \\
\text { regurg. }\end{array}$ \\
\hline & & & & & \multicolumn{4}{|c|}{ Severe Mitral Stenosis } & & & & & \\
\hline 7 & $38 \mathrm{M}$ & $4 \cdot 1(2 \cdot 3)$ & PCV 14 (29) & 一 & - & - & - & 一 & $37 / 16(23)$ & 2 & 50 & $1.0 \times 0.5$ & $\mathbf{0}$ \\
\hline 9 & $37 F$ & $2 \cdot 3(1 \cdot 4)$ & PCV 8 (33) & - & - & - & - & - & $30 / 13(18)$ & $4 \cdot 5$ & 63 & & 0 \\
\hline 11 & $44 \mathrm{~F}$ & $3.9(2.4)$ & PCV $14(33)$ & - & - & - & - & - & $35 / 17(23)$ & $2 \cdot 5$ & 40 & $0.8 \times 0.4$ & u \\
\hline 12 & $38 \mathrm{~F}$ & $2 \cdot 7(1 \cdot 9)$ & PCV $16(25)$ & 一 & 一 & 一 & - & 一 & $28 / 18(23)$ & $2 \cdot 5$ & $42 * *$ & $1.0 \times 0.5$ & 0 \\
\hline $\begin{array}{l}13 \\
15\end{array}$ & $\begin{array}{l}47 F \\
42 F\end{array}$ & $3 \cdot 4(2 \cdot 4)$ & PCV 14 (30) & - & 一 & - & - & - & $34 / 19(24)$ & 3 & 24 & $\begin{array}{l}0.75 \times 0.5 \\
0.75 \times 0.25\end{array}$ & $\begin{array}{l}0 \\
+\end{array}$ \\
\hline 16 & $41 \mathrm{M}$ & 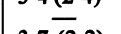 & & & & & & & 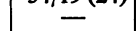 & & 23 & $1.0 \times 0.5$ & + \\
\hline 21 & 40F & $3 \cdot 7(2 \cdot 2)$ & LA 29 & $144 / 6$ & $93 / 67$ & $51(46)$ & 0.45 & 0.67 & 二 & - & 26 & $0.75 \times 0.5$ & + \\
\hline 24 & $42 \mathrm{M}$ & $3 \cdot 3 \overline{(2 \cdot 0)}$ & PCV $\overline{26} *$ & $\overline{-}$ & $=$ & $=$ & 二 & $=$ & $44 / 22(29)$ & $\overline{2^{*}}$ & $8+$ & $\begin{array}{l}\text { T1ght stenosis } \\
0.5 \times 0.3\end{array}$ & $\begin{array}{l}0 \\
0\end{array}$ \\
\hline 25 & $38 \mathrm{~F}$ & $2 \cdot 7(1 \cdot 8)$ & PCV 18 & 一 & - & 一 & - & 一 & $150 / 38(82)$ & $2 \overline{3} \cdot 5$ & $58^{*}$ & $0.5 \times 0.4$ & $\mathbf{0}$ \\
\hline $\begin{array}{l}26 \\
27\end{array}$ & $\begin{array}{l}46 \mathrm{~F} \\
40 \mathrm{~F}\end{array}$ & 二 & 二 & 二 & 二 & 二 & 二 & 二 & 二 & $=$ & $\begin{array}{l}20 \\
23\end{array}$ & $\begin{array}{l}0.2-0.3 \text { diam. } \\
0.5 \times 0.5\end{array}$ & $\begin{array}{l}\mathbf{0} \\
\mathbf{0}\end{array}$ \\
\hline 29 & $26 \mathrm{~F}$ & $\pi-$ & - & & & - & - & - & - & - & 64 & $0.5 \times 0.5$ & 0 \\
\hline $\begin{array}{l}30 \\
31\end{array}$ & $\begin{array}{l}34 \mathrm{~F} \\
32 \mathrm{~F}\end{array}$ & $\begin{array}{l}2 \cdot 7(1.9) \\
2 \cdot 8(1.8)\end{array}$ & $\begin{array}{l}\text { PCV 12 } \\
\text { PCV 17 (27) }\end{array}$ & $\stackrel{80 / 16}{-}$ & 72/60 & $8 † \ddagger$ & 二 & 二 & $66 / 38(50)$ & $\begin{array}{l}4 \cdot 5 \\
12\end{array}$ & $\overline{13}$ & $\begin{array}{l}1.0 \times 0.5 \\
\text { Tight stenosis }\end{array}$ & $\begin{array}{l}\mathbf{0} \\
\mathbf{0}\end{array}$ \\
\hline \multirow{12}{*}{$\begin{array}{r}1 \\
2 \\
4 \\
6 \\
8 \\
14 \\
17 \\
18 \\
19 \\
20 \\
22 \\
28 \\
32 \\
33\end{array}$} & \multirow{12}{*}{$\begin{array}{l}40 \mathrm{~F} \\
54 \mathrm{M} \\
48 \mathrm{~F} \\
35 \mathrm{M} \\
24 \mathrm{~F} \\
39 \mathrm{~F} \\
37 \mathrm{~F} \\
34 \mathrm{~F} \\
45 \mathrm{~F} \\
47 \mathrm{~F} \\
33 \mathrm{M} \\
39 \mathrm{~F} \\
36 \mathrm{~F} \\
48 \mathrm{~F}\end{array}$} & \multirow{5}{*}{$\begin{array}{l}5 \cdot 5 \overline{(3 \cdot 0)} \\
3 \cdot 7(2 \cdot 3) \\
2 \cdot 6(1 \cdot 7)\end{array}$} & \multirow{5}{*}{$\begin{array}{l}\text { PCV } 20 \\
\text { PCV 17 (22) } \\
\text { PCV 12 (22) }\end{array}$} & \multirow{3}{*}{$\begin{array}{l}20 \overline{1} / 17 \\
164 / 10\end{array}$} & \multirow{2}{*}{\multicolumn{4}{|c|}{ Moderate Mitral Stenosis }} & \multirow{4}{*}{\begin{tabular}{|l|}
$42 / 21(31)$ \\
$60 / 33(46)$ \\
$26 / 12(17)$
\end{tabular}} & \multirow{4}{*}{$\begin{array}{l}\overline{2} \\
8 \\
2\end{array}$} & \multirow{12}{*}{$\begin{array}{r}110 \\
96 \\
74 \\
51 \\
50 \\
29 \\
30 \\
19 \\
15 \\
83 \\
30 \\
16 \\
17\end{array}$} & \multirow{12}{*}{$\begin{array}{c}1.25 \times 1.0 \\
1.25 \times 0.5 \\
1.25 \times 1.0 \\
1.2 \times 1.0 \\
1.25 \times 0.3 \\
2.0 \times 0.2 \\
1.5 \times 0.3 \\
1.2 \times 0.8 \\
1.4 \times 0.75 \\
1.25 \times 0.5 \\
1.2 \times 0.5 \\
1.5 \times 1.0 \\
1.25 \times 0.6 \\
(1.4 \times 0.3) \|\end{array}$} & \multirow{12}{*}{$\begin{array}{l}0 \\
0 \\
0 \\
+ \\
+ \\
+ \\
0 \\
+ \\
+ \\
\pm \\
0 \\
\pm \\
0 \\
+\end{array}$} \\
\hline & & & & & \multirow{3}{*}{\multicolumn{2}{|c|}{\begin{tabular}{|c|c|}
$9 \overline{9} / 74$ & $102(76)$ \\
$82 / 57$ & $82(65)$
\end{tabular}}} & & & & & & & \\
\hline & & & & & & & \multirow{2}{*}{$\begin{array}{l}\overline{0.48} \\
0.58\end{array}$} & - & & & & & \\
\hline & & & & $164 / 10$ & & & & 二 & & & & & \\
\hline & & & & - & & - & - & & & & & & \\
\hline & & $2 \cdot 3(1 \cdot 5)$ & PCV 30 & - & - & - & - & - & $100 / 50(62)$ & 14 & & & \\
\hline & & $3.8(2.8)$ & PCY $\overline{30}$ & 二 & 二 & 一 & 一 & 二 & & & & & \\
\hline & & $\begin{array}{l}3 \cdot 8(2 \cdot 8) \\
3 \cdot 7(2 \cdot 1)\end{array}$ & $\begin{array}{l}P C D \\
P C V \\
P C\end{array}$ & 二 & 二 & 二 & 二 & 二 & $\begin{array}{l}84 / 35(51) \\
40 / 19(25)\end{array}$ & $\begin{array}{l}3.5 \\
2.5\end{array}$ & & & \\
\hline & & - & Tor & 二 & - & 二 & $\overline{-}$ & 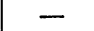 & 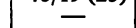 & & & & \\
\hline & & - & - & - & - & - & - & - & - & - & & & \\
\hline & & 二 & 二 & 二 & 二 & 二 & 二 & 二 & 二 & $\bar{z}$ & & & \\
\hline & & $2 \cdot 4(1 \cdot 5)$ & LA 33 & $114 / 7$ & $\begin{array}{c}92 / 69 \\
\text { (radial) }\end{array}$ & $22(39)$ & 0.45 & $0 \cdot 31$ & - & - & & & \\
\hline & & & & & & Aild Mitr & Sten & & & & & & \\
\hline $\begin{array}{l}3 \\
5\end{array}$ & $45 \mathrm{M}$ & $\begin{array}{l}7.5(5.0) \\
3.2(1.9)\end{array}$ & PCV 7 (15) & $169 / 5$ & $100 / 70$ & 69 (49) & 0.56 & 一 & $\begin{array}{l}23 / 11(16) \\
36 / 12(22)\end{array}$ & $\frac{1}{2 \cdot 5}$ & 96 & $\begin{array}{l}2.0 \times 1.0 \\
1.7 \times 1.0\end{array}$ & $\begin{array}{l}0 \\
+\end{array}$ \\
\hline 10 & $32 \mathrm{M}$ & - & LA 28 & $108 / 10$ & $63 / 32$ & 45 & - & & & & 22 & $2.0 \times 1.0$ & $t$ \\
\hline $\begin{array}{l}34 \\
35\end{array}$ & $\begin{array}{l}51 \mathrm{~F} \\
44 \mathrm{~F}\end{array}$ & $\begin{array}{l}6 \cdot 3(3 \cdot 8) \\
7 \cdot 0(4 \cdot 4)\end{array}$ & $\begin{array}{l}\text { LA } 10 \\
\text { LA } 24\end{array}$ & $\begin{array}{l}143 / 12 \\
200 / 9\end{array}$ & $\begin{array}{l}112 / 50 \\
100 / 65\end{array}$ & $\begin{array}{r}31(33) \\
100(62)\end{array}$ & $\begin{array}{l}1.0 \\
0.8\end{array}$ & $\begin{array}{l}1.5 \\
1.4\end{array}$ & - & - & 60 & $1.75 \times 0.75$ & + \\
\hline
\end{tabular}

* Case 24. P.C.V. pressure recorded at previous cardiac catheterization (4 years pre-operatively).

$\dagger$ Cases 24, 30. Pressure records overdamped.

₹ Case 30. Aortic systolic gradient recorded at post-operative left atrial puncture.

II Case 33. Mitral valve area measured at post-mortem examination.

** Gradient at mitral valvotomy (Cases 12 and 25 ).

TABLE IV

RESUMÉ OF HEMODYNAMIC OBSERVATIONS

\section{Cardiac Index}

Range 1.4-5.01./min. $/ \mathrm{m} .{ }^{2}$ Average $2 \cdot 31 . / \mathrm{min} . / \mathrm{m} .{ }^{2}$

Less than $2 \cdot 5$ in $16: 2 \cdot 6-5.01 . / \mathrm{min} . / \mathrm{m} .2$ in 5 patients.

\section{"Pulmonary Capillary Venous" or Left Atrial Pressure}

Range 7-33 mm. Average $19 \mathrm{~mm}$. 20-29 mm. in 5 patients Up to $12 \mathrm{~mm}$. in 5 patients $30 \mathrm{~mm}$. or more in 3 patients 13-19 $\mathrm{mm}$. in 9 patients

Aortic Peak Systolic Gradient*

$100 \mathrm{~mm}$. or more in 1 patient $75-99 \mathrm{~mm}$. in 3 patients $50-74 \mathrm{~mm}$. in 8 patients
$25-49 \mathrm{~mm}$. in 10 patients

Less than $25 \mathrm{~mm}$. in 13 patients

\footnotetext{
* At operation in 32 patients, at left atrial puncture in the other three.
} 


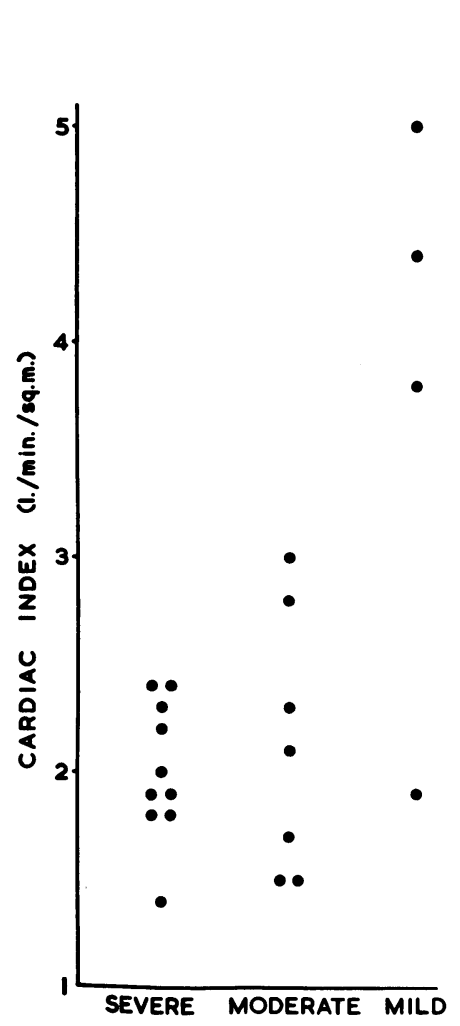

FIG. 1.-Cardiacindex (1./min./sq.m.) plotted against severity of mitral stenosis. Severe stenosis, with valve area $1.0 \times 0.5 \mathrm{~cm}$. or less; moderate, $1.0-1.5 \times 0.5-1.0$ $\mathrm{cm}$; and mild, $>1.5 \times 1.0 \mathrm{~cm}$.

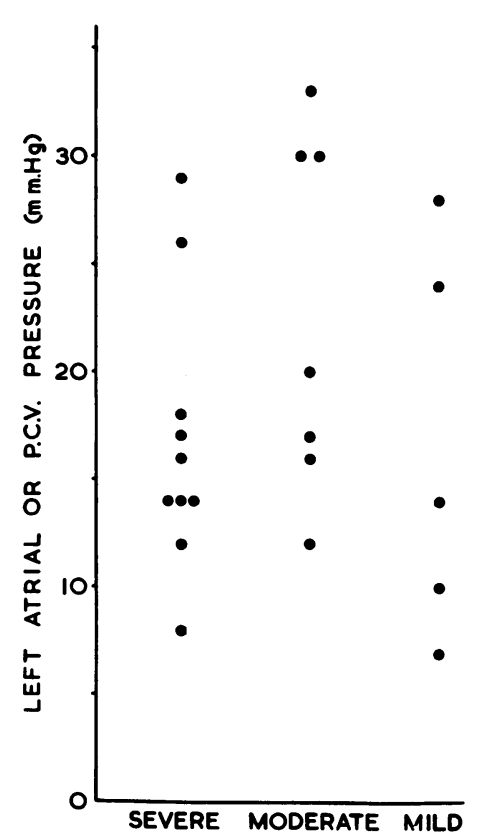

FIG. 2.- Left atrial or "pulmonary capillary venous" pressure plotted against severity of mitral stenosis, classified as in Fig. 1.

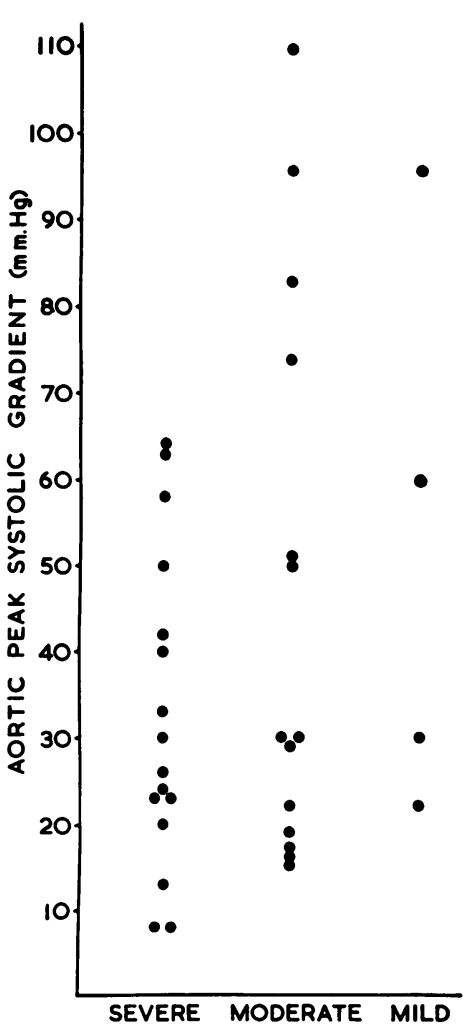

FIG. 3.-Aortic peak systolic gradient plotted against severity of mitral stenosis. Peak gradient measured at operation in 32 , and at left atrial puncture in the other 3 patients.

of the mitral stenosis. As would be expected, none of the patients with severe stenosis had a cardiac index of $2.51 . / \mathrm{min}$./sq. m. or more: many of those with moderate stenosis also had low cardiac indices. Only one patient with mild stenosis had a low cardiac index and he (Case 5) had significant mitral regurgitation and probably also some degree of left ventricular failure.

Not surprisingly, the patients with moderate and severe stenosis were found to have raised left atrial pressures (Fig. 2), except when the cardiac index was very low (Cases 6, 9, and 30). Of those 3 patients with mild stenosis and raised left atrial pressures, one (Case 35) had a high output (cardiac index 4.4 l./min./sq. m.), one had left ventricular failure (Case 10) and the other significant regurgitation.

None of the patients with severe mitral stenosis had an aortic valve gradient exceeding $64 \mathrm{~mm}$. (Fig. 3); all those with gradients exceeding $70 \mathrm{~mm}$. were found to have mild or moderate mitral stenosis. There were, however, many patients with mild or moderate mitral stenosis and lesser aortic gradients; in six these were less than $25 \mathrm{~mm}$. but in 2 of the 3 in whom the cardiac index was measured, this was low.

The Aortic Valve. The evidence concerning the severity of the aortic stenosis is unavoidably incomplete. Twelve of the 35 patients have had no aortic valvotomy and in these there is no operative assessment of the stenosis, apart from the measurement of the gradient. In one (Case 33) 
who died, the aortic valve at necropsy was very tightly stenosed $(0.6 \times 0.3 \mathrm{~cm}$.) but not calcified; her aortic valve peak systolic gradient at left atrial puncture was only $22 \mathrm{~mm}$. (mean gradient $39 \mathrm{~mm}$.), cardiac index $1.51 . / \mathrm{min} . / \mathrm{sq}$. m., and calculated aortic valve area $0.45 \mathrm{sq} . \mathrm{cm}$. One other (Case 29), whose aortic valve gradient at mitral valvotomy had been $64 \mathrm{~mm}$., had a left atrial puncture five years later and the calculated aortic valve area then was $0.50 \mathrm{sq} . \mathrm{cm}$. : there was no aortic regurgitation and there can be little doubt that this patient also had severe aortic stenosis. A third (Case 32), with an aortic valve gradient of $17 \mathrm{~mm}$. at mitral valvotomy, had a left atrial puncture eight years later, when the aortic gradient was $24 \mathrm{~mm}$., cardiac index $2.21 . / \mathrm{min} . / \mathrm{sq} . \mathrm{m}$., and calculated aortic valve area 0.94 sq. $\mathrm{cm} .:$ this patient had only trivial aortic regurgitation and she also must have critical aortic stenosis.

The other 23 patients have had an aortic valvotomy, performed at the time of the mitral valvotomy in all but Cases 12 and 25. In six of these (Cases 1, 2, 3, 4, 20, and 35), gradients exceeding $80 \mathrm{~mm}$. were found either before or at operation: a gradient of this order would be accepted as evidence of critical stenosis in a patient with lone aortic stenosis. In two others (Cases 6 and 10), severe aortic stenosis was still present at necropsy. The surgeon's assessment of the severity of stenosis at valvotomy depends on the ease with which bougies and dilator can be passed through the valve orifice: this inevitably gives a rough impression and in many of the cases, the operation record does not enable an assessment to be made in retrospect.

However, where the average diameter of the orifice was reported as $1.25 \mathrm{~cm}$. or less, one can reasonably conclude that the stenosis was critical, the valve area being probably less than 1.0 sq. $\mathrm{cm}$. (all those with gradients exceeding $80 \mathrm{~mm}$. had smaller orifices than this). By this criterion, at least 5 others (Cases 8, 12,17, 21, and 25) had critical stenosis. In those seven cases with undoubted critical stenosis but lesser aortic gradients, the gradients at operation were $51,22,50,42,30,26$, and $58 \mathrm{~mm}$. and the cardiac indices $1 \cdot 7,1 \cdot 9,2 \cdot 2$, and $1 \cdot 81 . / \mathrm{min} . / \mathrm{sq} . \mathrm{m}$. in those four where the measurement was made. Indirect evidence of the severity of the aortic stenosis in other cases will be presented later.

\section{Discussion}

In this series of cases, combined mitral and aortic stenosis resembles mitral stenosis in its preponderance of women and the high incidence of a past rheumatic history. Thus Wood (1954) had twice as many women as men in his series of 300 cases of mitral valve disease and a past history of rheumatism in 68 per cent. On the other hand, Baker and Somerville's (1959) series of 50 operated cases of aortic stenosis without significant mitral valve disease contained only 7 with a rheumatic history and men outnumbered women by 3.5 to 1 . The age incidence in this series was roughly the same as that in mitral stenosis, though the average age (40 years) was slightly higher than that of Wood's (1954) operated patients with mitral stenosis (37 years): there were fewer patients in the second and sixth decades than among those with lone aortic stenosis.

Likewise, the symptoms in these cases were predominantly those of mitral stenosis: angina and syncope, which are characteristic of severe lone aortic stenosis, were relatively infrequent. Thus angina occurred in 34 of 50 patients with lone aortic stenosis (Baker and Somerville, 1959) but in only 6 of the 35 in this series; syncope and "near-syncope" occurred in 33 of the former, but in only 8 of the present series. Recurrent bronchitis, hæmoptysis, and systemic embolism, which are common in mitral stenosis but rare in lone aortic stenosis, occurred in many of the patients in this series. Uricchio et al. (1959) have also reported a low incidence of angina (23\%), vertigo $(25 \%)$, and syncope $(16 \%)$ in their series of 141 patients with combined mitral and aortic stenosis; on the other hand, dyspnœa, fatigue, œdema, hæmoptysis, and emboli occurred as frequently as in pure mitral stenosis.

Certain radiological and cardiographic features of combined mitral and aortic stenosis are also strikingly different from those of lone aortic stenosis. L.V.H., evident on both radiograph and cardiogram, is almost invariable in lone aortic stenosis that comes to operation (Baker and Somerville, 1959) but was present in only 11 of this series and in 9 was only slight. Likewise, Uricchio et al. 
(1959) found cardiographic L.V.H., with or without R.V.H., in only 22 per cent of their cases. Calcification of the aortic valve was present in all Baker and Somerville's patients above the age of 30 years but in only one-fifth of this series. Post-stenotic dilatation was seen in only 4 patients out of 35, in contrast with all but 1 of 43 patients with lone aortic valve stenosis (Baker and Somerville, 1959).

A possible explanation for these differences which could be advanced is that combined mitral and aortic stenosis is due to rheumatic heart disease, that lone aortic stenosis has a different ætiology, and that rheumatism rarely causes severe stenosis of the aortic valve. It is certain that many cases of lone aortic stenosis in childhood and early adult life have congenital aortic stenosis, in some cases possibly on the basis of a bicuspid valve (Bacon and Matthews, 1959; Bentivoglio et al., 1960), though a few are unquestionably rheumatic. The rarity of calcification of the aortic valve in those patients with co-existing mitral stenosis might reasonably be attributed to a lesser severity of the stenosis in the majority of cases and to the different pathological process. It could be that, in rheumatic heart disease, severe mitral stenosis and the symptoms resulting from it develop more rapidly than severe aortic stenosis. It evidently takes up to 30 years for calcification to develop in a congenitally narrowed aortic valve; one might expect that calcification would occur correspondingly later in rheumatic aortic stenosis but in this series the ages of the patients with calcified aortic valves ranged from 32 to 54 years, the average (43 years) not being significantly different from that of the series as a whole. A further possibility is that severe aortic and severe mitral stenosis in the same patient are not compatible with life and are therefore rarely seen together; though aortic stenosis with left ventricular failure and mitral stenosis is a lethal combination, there is no doubt that in some cases in this series both lesions were of critical severity.

While these considerations may be relevant, the main cause for the observed clinical differences between combined mitral and aortic stenosis and lone aortic stenosis is the difference in cardiac output in the two groups. Whereas the patients in this series with severe mitral stenosis accompanying aortic stenosis all have subnormal cardiac indices, Hancock and Fleming (1960) found that the cardiac index in their patients with moderate or severe lone aortic stenosis was within the normal range or above it in all except 7 of 41 patients; 5 of the 7 exceptions had frank left ventricular failure. Gorlin and Gorlin (1951), in evolving their formula for the calculation of valve area from hæmodynamic data, made the assumption, based on hydrodynamic principles, that for a given size of orifice, the mean gradient across the valve (in systole in the case of the aortic valve) was proportional to the square of the flow through it. Thus in order to double the systemic output it is necessary to increase the valve gradient fourfold; a patient with a gradient of $25 \mathrm{~mm}$. at an output of 2.51 ./min. would be expected to require a gradient of $100 \mathrm{~mm}$. to maintain an output of $5.01 . / \mathrm{min}$. The approximate validity of Gorlin's formula when applied to the aortic valve is shown by the remarkably close agreement between calculated and observed valve area in the series of Baker and Somerville (1959).

In Fig. 4, the cardiac index in those cases in the present series when it has been measured is plotted against the aortic peak systolic gradient. Unfortunately, simultaneous observations are available in only a few cases, but in those patients in whom the gradient was measured both before and at operation, the differences were not very great, and Brock (1957) has found a reasonably close correlation between pressures recorded before operation and those obtained at operation in aortic stenosis. In many of the patients, records were only made using slow paper speeds so that mean gradients could not be measured; Hancock and Fleming (1960) found that the mean gradient is usually about 80 per cent of the peak gradient, though sometimes actually exceeding it when the gradient is relatively small. These considerations do not however significantly affect the conclusions to be drawn.

The curve shows aortic mean systolic gradient plotted against cardiac index in an imaginary case of critical aortic stenosis with a valve area of $0.5 \mathrm{sq} . \mathrm{cm} . / \mathrm{sq} . \mathrm{m}$. (assuming a systolic ejection period of $25 \mathrm{sec}$./min.); the values for aortic gradient were calculated using the formula of Gorlin and Gorlin (1951). Points above this line can thus be taken to correspond to severe degrees of aortic stenosis. From this it can be seen that when the cardiac index is less than $2.51 . / \mathrm{min}$./sq. m., an aortic systolic 


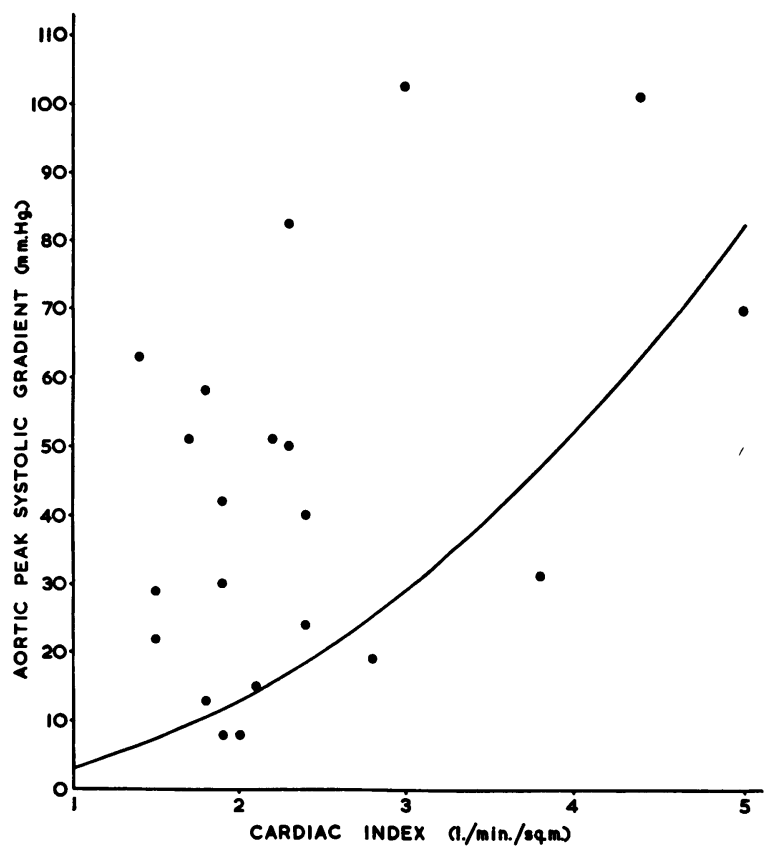

FIG. 4.-Aortic peak systolic gradient plotted against cardiac index. Cardiac index in all cases obtained before operation. Aortic gradient measured at left atrial or ventricular puncture in those cases where this was performed (Cases 2, 3, 4, 21, 30, 33, 34, and 35) and at operation in all the others. Curve represents aortic valve area of $0.5 \mathrm{sq} . \mathrm{cm}$. (per sq. m.) and systolic ejection period $25 \mathrm{sec}$./min.; aortic mean systolic gradient calculated using Gorlin's formula.

gradient of 20 to $25 \mathrm{~mm}$. or more probably represents severe stenosis, the exact figure depending on the duration of the systolic ejection period (related to heart rate) and the relation of peak to mean gradient in the individual case. Those patients with the largest gradients had the highest cardiac indices: as has already been observed, these are the patients with only mild or moderate mitral stenosis. In addition to the patients already noted to have critical aortic stenosis, it seems likely that Cases 5, 7, 9, 11, 12, and 14 also had stenosis of a similar degree. On the other hand, Cases $18,24,30$, and 34 probably had only mild or moderate stenosis and Cases 15, 19, and 31 were borderline.

The fact that, in these cases, the aortic gradient measured at operation is insufficient evidence on which to make a reliable assessment of the severity of the aortic stenosis is well illustrated by several examples from this series.

Case 10. At pre-operative left atrial puncture, there was an aortic peak systolic gradient of $45 \mathrm{~mm}$.; no cardiac output measurement was made, but he was hypotensive and the output probably low. At operation, the gradient was initially only $8 \mathrm{~mm}$. when there was profound hypotension and the heart action was very feeble: following mitral valvotomy and the intracardiac injection of calcium chloride, the gradient was $22 \mathrm{~mm}$. (L.V. 103/16; aorta 81/62). At necropsy, three years later, severe aortic stenosis was found.

Case 21. At pre-operative left atrial puncture, there was an aortic peak systolic gradient of $51 \mathrm{~mm}$.; the cardiac output was $3.71 . / \mathrm{min}$. (index $2.21 . / \mathrm{min}$./sq. m.) and the calculated aortic valve area $0.45 \mathrm{sq} . \mathrm{cm}$. At operation, the gradient was initially $26 \mathrm{~mm}$. and following mitral valvotomy only $15 \mathrm{~mm}$; the aortic valve orifice was severely stenosed and was estimated to be $1.1 \mathrm{~cm}$. in diameter. She also had severe mitral stenosis with slight regurgitation.

Case 25. At operation in 1951, the aortic peak systolic gradient was $58 \mathrm{~mm}$. before and only $21 \mathrm{~mm}$. 
after mitral valvotomy; the mitral stenosis was severe and the cardiac index at pre-operative right heart catheterization $1.81 . / \mathrm{min}$./sq. $\mathrm{m}$. Aortic valvotomy was not done at that time. Improvement was followed by deterioration and she was re-investigated in 1960; at left atrial puncture, the aortic gradient was $67 \mathrm{~mm}$. (L.V. 185/10; aorta 118/71), the cardiac index $2.41 . / \mathrm{min} . / \mathrm{sq} . \mathrm{m}$., and the calculated aortic valve area was 0.49 sq. $\mathrm{cm}$. At re-operation, the aortic valve gradient before valvotomy was only $32 \mathrm{~mm}$. and the aortic orifice was estimated to be $1.25 \times 1.0 \mathrm{~cm}$.

Case 29. At operation in 1953, the aortic peak systolic gradient was $64 \mathrm{~mm}$. before and $27 \mathrm{~mm}$. after mitral valvotomy; mitral stenosis was severe. Though severe mitral regurgitation resulted from the operation, she did well for three years, only to become totally incapacitated following pregnancy and the onset of atrial fibrillation. At left atrial puncture in 1958, the peak systolic gradient was only $16 \mathrm{~mm}$. (mean gradient $34 \mathrm{~mm}$.) but the cardiac index was extremely low $(1.4 \mathrm{l} . / \mathrm{min} . / \mathrm{sq} . \mathrm{m}$.) and there was clinical and hæmodynamic evidence of right ventricular failure; the calculated aortic valve area was $0.5 \mathrm{sq} . \mathrm{cm}$., indicating (in the absence of aortic regurgitation) severe stenosis. Re-operation was not advised, in view of severe mitral regurgitation.

Case 35. At pre-operative left atrial puncture, the aortic peak systolic gradient was $100 \mathrm{~mm}$., the cardiac output being high $(7.01 . / \mathrm{min}$.; index $4.4 \mathrm{l} / \mathrm{min}$./sq. m.). At operation, the gradient was only $60 \mathrm{~mm}$. and the stenosis though critical was not thought to be very severe. The pre-operative calculated mitral valve area was 1.4 sq. $\mathrm{cm}$. and at operation, the mildness of the mitral stenosis was confirmed (orifice $1.75 \times 0.75 \mathrm{~cm}$.).

These cases illustrate the dependence of the aortic valve gradient on the cardiac output. Conditions resulting in a low output, namely severe mitral stenosis, severe mitral regurgitation, left ventricular or congestive cardiac failure, including the deterioration in cardiac action during operation in some seriously ill patients, are commonly associated with low aortic gradients. The gradient was sometimes noted at operation to have fallen after the performance of mitral valvotomy, contrary to expectation; this probably was due to the effects of intracardiac manipulation in a heart with unrelieved aortic stenosis.

Uricchio et al. (1959) measured the cardiac output in only 8 patients in their series, in all of whom it was subnormal. Two with severe aortic stenosis (and moderate mitral stenosis) had aortic gradients of only 17 and $35 \mathrm{~mm}$. Four had an aortic gradient of $90 \mathrm{~mm}$. or more: one had only mild mitral stenosis: but the other three all had severe mitral stenosis and exceptionally severe aortic stenosis (calculated aortic valve area $0.2 \mathrm{sq} . \mathrm{cm}$. in all), a combination not encountered in the present series.

The effects of severe mitral stenosis on the clinical and hæmodynamic features of aortic stenosis can now be more clearly understood. The low cardiac output of severe mitral stenosis results in a low aortic valve gradient and hence in a relatively modest increase in left ventricular systolic pressure. The left ventricle is thus protected and not called upon to sustain a normal or high output in the face of a high systolic pressure. This explains the rarity of more than slight left ventricular hypertrophy and the infrequency of angina; anginal pain may however occur in mitral stenosis in the absence of aortic stenosis, sometimes as a result of previous embolism. Calcification of the aortic valve probably results from the effects of hæmodynamic stresses on a valve deformed by disease or congenital maldevelopment: when the gradient is small, these stresses are less and it is understandable that calcification should occur less readily. Post-stenotic dilatation of the first part of the aorta is attributed to the effects of a high velocity jet on the aortic wall: when the output is low and the gradient small, this jet effect is minimized. Syncope on exertion in aortic stenosis is not fully understood; ventricular asystole may sometimes be the cause (Leak, 1959). Failure of the cardiac output to increase on exertion cannot by itself be responsible as this occurs in uncomplicated severe mitral stenosis, in which syncope is unusual. Donald (1959) has shown that the patient with severe mitral stenosis and a fixed low cardiac output is able to maintain cerebral blood flow during exercise, by a sharp reduction in blood flow to the non-exercising muscles and in splanchnic and renal blood flow greatly in excess of the normal response, and by the absence of the cutaneous vasodilatation occurring during exercise in normal subjects. Regional blood flows have not been studied in lone aortic stenosis but it is possible that these vascular responses to exercise do not occur when the resting output is normal: the co-existence of mitral stenosis with low resting output may then be responsible for initiating the mechanisms required to maintain cerebral blood flow during exercise. This point requires further study. 
The presence of mild or moderate mitral stenosis with normal cardiac output does not have the same effect on the clinical manifestations of aortic stenosis. This correlates with the not infrequent occurrence of substantial aortic gradients in such patients. Syncope or "near syncope" occurred in 6, cardiographic L.V.H. in 10, and aortic valve calcification in 7, out of 19 patients with mild or moderate mitral stenosis: in the 16 with severe mitral stenosis, syncope or "near syncope" occurred in 2, cardiographic L.V.H. in 3, and aortic valve calcification in 1 patient.

The characteristic physical signs of aortic stenosis may also be inconspicuous in the presence of severe mitral stenosis. Thus the systolic murmur is rarely as loud as when aortic stenosis is the sole lesion and a thrill is less commonly observed; clinical evidence of left ventricular hypertrophy may be absent; and the small volume of the arterial pulse may obscure its slow rate of rise. As a result, significant aortic stenosis may indeed be entirely overlooked. Uricchio and Likoff (1957) reported three patients in whom, following mitral valvotomy, left ventricular enlargement and the auscultatory features of aortic valve disease (dominant stenosis) became more obvious; this was also observed in Cases 12 and 25 in this series, the only two patients in whom aortic valvotomy was undertaken at a later date than mitral valvotomy.

One conclusion to be drawn from these observations is that an aortic peak systolic gradient at operation of 20 to $25 \mathrm{~mm}$. or more may be due to critical aortic stenosis, requiring operative relief: Wood (1958) and Uricchio et al. (1959) expressed similar views. When combined mitral and aortic stenosis is suspected clinically, even when the evidence for the latter is relatively slight, full preoperative hæmodynamic assessment by left heart catheterization should be undertaken, with measurement of aortic and mitral gradients, cardiac output, and systolic ejection and diastolic filling periods, and with calculation of estimated valve areas. In this way, the need for aortic valvotomy can be more accurately judged than by mere observation of the gradient at operation.

The presence of even severe aortic stenosis may have little effect on the hæmodynamic manifestations of severe mitral stenosis. The left ventricle, being protected by the reduced cardiac output, rarely fails and the left atrial pressure is usually of the same order as when mitral stenosis is present alone. However, when left ventricular failure, with a raised left ventricular diastolic pressure, does occur in aortic stenosis, even a mild degree of mitral stenosis with a small mitral diastolic gradient may result in a very high left atrial pressure. In this series, Case 33, with severe stenosis of both valves, developed intractable pulmonary œdema and died while awaiting operation; in her case, the presence of significant mitral regurgitation may have contributed to this outcome.

The most important effect of aortic stenosis is that the systolic murmur, which is commonly well heard at the apex, may lead to the erroneous conclusion that the mitral valve is mainly incompetent. The presence of even a soft mitral systolic murmur may obscure the fact that the apical murmur is basically an ejection murmur. In this series, at least two patients (Cases 2 and 21) were operated on for aortic stenosis with the firm clinical impression that mitral regurgitation was dominant.

Case 21. This patient had a small volume pulse, clinical evidence of left but not right ventricular hypertrophy, an apical systolic murmur, and a quiet relatively short diastolic rumble: there was no opening snap and the first sound was only slightly accentuated. At the aortic area, there were systolic and soft early diastolic murmurs. At operation, the mitral valve was severely stenosed $(0.75 \times 0.5 \mathrm{~cm}$.) but the orifice was rigid: there was a small regurgitant jet, but stenosis was clearly dominant. Mitral and aortic valvotomies were performed.

Case 25 had a successful mitral volvotomy, severe aortic stenosis being left untouched. When she later deteriorated, the physical signs were interpreted as indicating important mitral regurgitation, in addition to aortic stenosis. At left atrial puncture, the left atrial pulse form was normal and unaffected by the infusion of nor-adrenalin (Braunwald et al., 1958) and the dye-dilution curve following left atrial injection did not suggest mitral regurgitation (Hancock, 1959a).

The raised left ventricular systolic pressure occurring with aortic stenosis results in an increased gradient across the mitral valve in systole. Thus, if the valve mechanism allows even slight regurgitation, the magnitude of the regurgitant flow will be increased. This is especially so when the mitral stenosis is mild and the aortic gradient large, and is particularly likely to occur after the successful surgical relief of mitral stenosis; the incidence of serious postoperative mitral regurgitation was unusually high (Honey, 1961). 


\section{SUMMARY AND CONCLUSIONS}

Certain clinical, radiological, cardiographic, and hæmodynamic findings have been studied in 35 patients with dominant or pure stenosis of both aortic and mitral valves. The cases with the highest aortic valve gradients usually have only mild or moderate mitral stenosis. When severe mitral stenosis and severe aortic stenosis co-exist, the aortic gradient is usually only small or moderate, a finding attributed to the low cardiac output. These observations largely account for the low incidence of angina and syncope, of cardiographic and radiological evidence of left ventricular hypertrophy, of post-stenotic dilatation of the aorta, and of calcification of the aortic valve. Clinically significant aortic stenosis may be overlooked and the mitral valve lesion may be erroneously thought to be dominant regurgitation.

When the aortic peak systolic gradient is 20 to $25 \mathrm{~mm}$. or more, in the presence of severe mitral stenosis, critical aortic stenosis requiring valvotomy may be present. Correct evaluation of a gradient of this order, obtained at mitral valvotomy, is difficult; and accurate assessment requires preoperative left heart catheterization, with measurement of valve gradients and cardiac output and calculation of valve areas.

The patients on whom this study is based were under the care of Sir Russell Brock, Dr. M. Campbell, C. G. Baker, and D. C. Deuchar, and Mr. R. H. F. Brain, and I am indebted to them for the opportunity of undertaking this investigation. I would also like to thank Miss J. Howard for help with the illustrations and Miss P. Wright for secretarial assistance.

\section{REFERENCES}

Bacon, A. P. C., and Matthews, M. B. (1959). Quart. J. Med., 28, 545.

Baker, C. G., Brock, R. C., Campbell, M., and Wood, P. (1952). Brit. med. J., 1, 1043.

- and Somerville, J. (1959). Guy's Hosp. Rep., 108, 101.

Bentivoglio, L. G., Sagarminaga, J., Uricchio, J., and Goldberg, H. (1960). Brit. Heart J., 22, 321.

Björk, V. O., Malmström, G., and Uggla, L. G. (1954). Ann. Surg., 138, 718.

Braunwald, E., Welch, G. H., and Morrow, A. G. (1958). J. clin. Invest., 37, 35.

Brock, R. C. (1957). Brit. med. J., 1, 1019.

-, Milstein, B. B., and Ross, D. N. (1956). Thorax, 11, 163.

Donald, K. W. (1959). Brit. med. J., 1, 985 .

Gorlin, R., and Gorlin, S. G. (1951). Amer. Heart J., 41, 1.

Hancock, E. W. (1959a). Brit. Heart J., 21, 389.

- (1959b). Guy's Hosp. Rep., 108, 349.

—, and Fleming, P. R. (1960), Quart. J. Med., 29, 209.

Honey, M. (1961). Guy's Hosp. Rep., Awaiting publication.

Leak, D. (1959). Brit. Heart J., 21, 289.

Uricchio, J. F., and Likoff, W. (1957). New Engl. J. Med., 256, 199. , Goldberg, H., Sinah, K. P., and Likoff, W. (1959). Amer. J. Cardiology, 4, 479.

Wood, P. (1954). Brit. med. J., 1, 1051.

(1958). Amer. J. Cardiology, 1, 553. 